Research Paper

\title{
Facial Soft Tissue Changes after Maxillary Impaction and Mandibular Advancement in High Angle Class II Cases
}

\author{
Barış Aydil ${ }^{\bowtie}$, Nedim Özer², Gülnaz Marşan³ \\ 1. Istanbul University, Faculty of Dentistry, Department of Maxillofacial Surgery, Istanbul, TURKEY. \\ 2. Okmeydani Dental Hospital, Department of Maxillofacial Surgery, Istanbul, TURKEY. \\ 3. Istanbul University, Faculty of Dentistry, Department of Orthodontics, Istanbul, TURKEY.
}

$\triangle$ Corresponding author: Dr. Barış Aydil, Istanbul University, Faculty of Dentistry, Department of Maxillofacial Surgery, Çapa, 34093 , Istanbul, Turkey. E-mail: barisaydil@yahoo.com Phone: +902124142020, Fax: +902125312230

( ) Ivyspring International Publisher. This is an open-access article distributed under the terms of the Creative Commons License (http://creativecommons.org/ licenses/by-nc-nd/3.0/). Reproduction is permitted for personal, noncommercial use, provided that the article is in whole, unmodified, and properly cited.

Received: 2012.02.17; Accepted: 2012.06.03; Published: 2012.06.09

\begin{abstract}
The aim of this study was to determine the vertical and anteroposterior alterations in the soft, the dental and the skeletal tissues associated with the facial profile after Le Fort I maxillary impaction in conjunction with sagittal split osteotomy for mandibular advancement performed in patients with a high angle Class II skeletal deformity.

The study population consists of 21 patients (II females and 10 males, mean age $24.5 \pm 1.6$ years) who underwent Le Fort I maxillary impaction in conjunction with sagittal split osteotomy for mandibular advancement. Lateral cephalograms were obtained prior to the surgery and I. $3 \pm 0.2$ years postoperatively. Wilcoxon test was performed to compare the pre- and postsurgical cephalometric measurements. Pearson correlation test was carried out to determine the relative changes in skeletal, dental and the facial soft tissues.

The insignificant decrease in the nasolabial angle was correlated with the significant decrease in the vertical position of the nose due to the nasal protraction noticed after bimaxillary surgery. The retraction of both the upper lip and the upper incisors was correlated with the insignificant decrease in the columella-lobular angle. The insignificant decrease in both the vertical height of the mandibular $B$ point and the lower incisors was correlated with the insignificant decrease in vertical height of the soft tissue pogonion, attributable to the resulting superior movement of the soft tissues of the chin and the counter clockwise rotation of the mandible after maxillary impaction and bilateral sagittal split osteotomy, respectively.

Le Fort I maxillary impaction in conjunction with mandibular sagittal split osteotomy for mandibular advancement significantly affected the vertical and anteroposterior positions of the maxilla and the mandible, respectively. When performed in combination, these surgical techniques may efficiently alter the position of upper incisor and the nasal position in both vertical and anteroposterior directions. Bimaxillary orthognathic surgery seems to be an efficient method for obtaining satisfactory results in the appearance of the soft, the dental and the skeletal tissues associated with the facial profile in patients with high angle Class II skeletal deformity.
\end{abstract}

Key words: vertical and anteroposterior alterations, Le Fort I maxillary impaction, Class II skeletal deformity.

\section{Introduction}

Orthognathic surgery is carried out to correct the congenital or the acquired deformities of the jaws.1,35
The capacity to alter the appearance of the facial profile increases when orthognathic surgery is performed 
in conjunction with orthodontics. The alterations in features of the facial soft tissues are confined to the lower third of the face when orthodontic treatment is carried out alone. However both the middle and lower thirds of the face can be altered efficiently when orthodontic treatment is performed in conjunction with orthognathic surgery. $1,35,37,41$ The identification of the aesthetic factors and the prediction of the final profile of the facial soft tissues play important roles in planning the orthognathic treatment.

Numerous studies have attempted to quantify the changes in the facial soft tissues after orthognathic surgery. ${ }^{1-11,13-34,37,38}$ While some studies reported on the changes in soft tissues associated with maxillary intrusion 12,32,35,39 others evaluated the outcomes of orthognathic surgery for mandibular advancement. $3,4,17,20,25,40,41$ The aim of this study was to determine the vertical and anteroposterior alterations in the soft, the dental and the skeletal tissues associated with the facial profile after Le Fort I maxillary impaction in conjunction with sagittal split osteotomy for mandibular advancement performed in patients with a high angle Class II skeletal deformity.

\section{Patients and Methods}

The study population consists of 21 patients (11 females and 10 males, mean age $24.5 \pm 1.6$ years) with a high angle Class II skeletal deformity who underwent Le Fort I maxillary impaction in conjunction with sagittal split osteotomy for mandibular advancement. The patients with a trauma, a congenital defect or a syndrome, and those who underwent soft tissue surgery (e.g. rhinoplasty) were excluded from the study. It was judged that an ethical approval was not required since the study involved retrospective analysis of the anonymized records.

All patients received pre- and post-surgical orthodontic treatment in the Department of Orthodontics, Faculty of Dentistry, Istanbul University, Istanbul. All patients were treated by Le Fort I maxillary impaction in conjunction with sagittal split osteotomy for mandibular advancement by the same surgeons in the Department of Maxillofacial Surgery, Okmeydani Dental Hospital, Istanbul.

In order to achieve a Le Fort I maxillary impaction, a horizontal incision was performed above the reflection of the sulcus. Subsequently, the nasal spine was subperiosteally degloved and the separation of the septum was accomplished by means of a guarded osteotome. The anterior nasal spine was left intact in all patients. A bilateral sagittal split osteotomy was also performed for mandibular advancement.

\section{Cephalometric analysis}

Lateral cephalograms were taken prior to surgery and $1.3 \pm 0.2$ years postoperatively. All of the cephalograms were evaluated by the same examiner. In order to eliminate possible transient changes in the healing soft tissues, the radiographs were taken $1.3 \pm 0.2$ years postoperatively and subsequent to the removal of orthodontic devices. All radiographs were taken while the teeth were in centric occlusion and the lips in repose.

The pre- and postsurgical (T1 and T2) lateral cephalograms were manually traced by the same examiner. The cephalometric reference points were determined on an acetate tracing paper. The horizontal reference line was determined by drawing a line in 7 degrees to the sella-nasion (S-N). A perpendicular line to the horizontal reference line at the nasion point was determined as the vertical reference line (Figure 1). These reference lines were transferred to the lateral cephalogram taken postoperatively. In the pre- and postsurgical cephalograms, the hard and soft tissue landmarks were determined by measuring in millimeters their distances to the horizontal and vertical reference lines. The differences in the distances of the hard and soft tissue landmarks were recorded as the changes attributable to the surgery. The abbreviations of the soft and hard tissue landmarks have been listed in Table 1.

Table I: Descriptions of the abbreviations for the hard and the soft tissue landmarks.

\begin{tabular}{|c|c|}
\hline APOINTAP & Anteroposterior movement of the A-point, \\
\hline ITIPAP & Anteroposterior movement of the upper incisal tip, \\
\hline NASALAP & The nasal anteroposterior movement, \\
\hline APOINTSI & Superoinferior movement of the A-point, \\
\hline ITIPSI & Superoinferior movement of the upper incisal tip, \\
\hline NASALSI & The nasal superoinferior movement, \\
\hline NLA & Nasolabial angle, \\
\hline CLA & Columella lobular angle, \\
\hline L1TIPAP & Anteroposterior movement of the lower incisor, \\
\hline L1TIPSI & Superoinferior movement of the lower incisor, \\
\hline $\begin{array}{l}\text { Labiomental } \\
\text { angle }\end{array}$ & $\begin{array}{l}\text { Lower lip (Li)-Labiomental fold-Soft tissue pogo- } \\
\text { nion (Soft Pog) angle, }\end{array}$ \\
\hline BPOINTSP & Superoinferior movement of the B-point, \\
\hline BPOINTAP & Anteroposterior movement of the B-point. \\
\hline
\end{tabular}

The length of S-N was measured on both the preand postsurgical cephalograms. Only were the cases with no change in the length of S-N included in the study. The nasion horizontal and vertical were chosen as the reference planes. A vertical line, which passed 
through the nasal tip, to the $\mathrm{S}-\mathrm{N}$ was selected to evaluate the vertical and horizontal movements of the nasal tip.

The T2 cephalogram was superimposed on the T1 cephalogram by coinciding the cranial base which is a stable reference point. The movements in the anterior and superior directions were assigned positive values whereas the movements in the posterior and inferior directions were assigned negative values. The nasolabial angle (NLA) and the columella-lobular angle (CLA) were drawn to measure the soft tissue profile of the nose. The NLA was determined by intersecting the lines from subnasale point to both the columella point and the labrale superius point. The CLA was the angle that formed at the junction of the columella with the infratip lobule.

In order to assess the intraexaminer reliability, the tracing of the cephalograms were repeated by the same examiner 1 month later.

\section{Statistical analysis}

Statistical analysis was performed by means of a statistical software (NCSS-Number Cruncher Statistical System, Utah, USA, 2007). Wilcoxon test was performed to compare the pre- and post-surgical measurements. Pearson correlation test was performed to evaluate the relative changes between the skeletal, the dental and the facial soft tissues. A p value less than 0.05 was considered statistically significant.

\section{Error of the method}

The values for the re-traced films were analyzed through the Dahlberg Formula that is "Error of the method $^{2}=\Sigma \mathrm{d}^{2} / 2 \mathrm{n}$ ", where $d$ is the difference between 2 measurements and $n$ is the number of double determinations. ${ }^{36}$ The error of the method was no greater than 0.5 degree and millimeter.

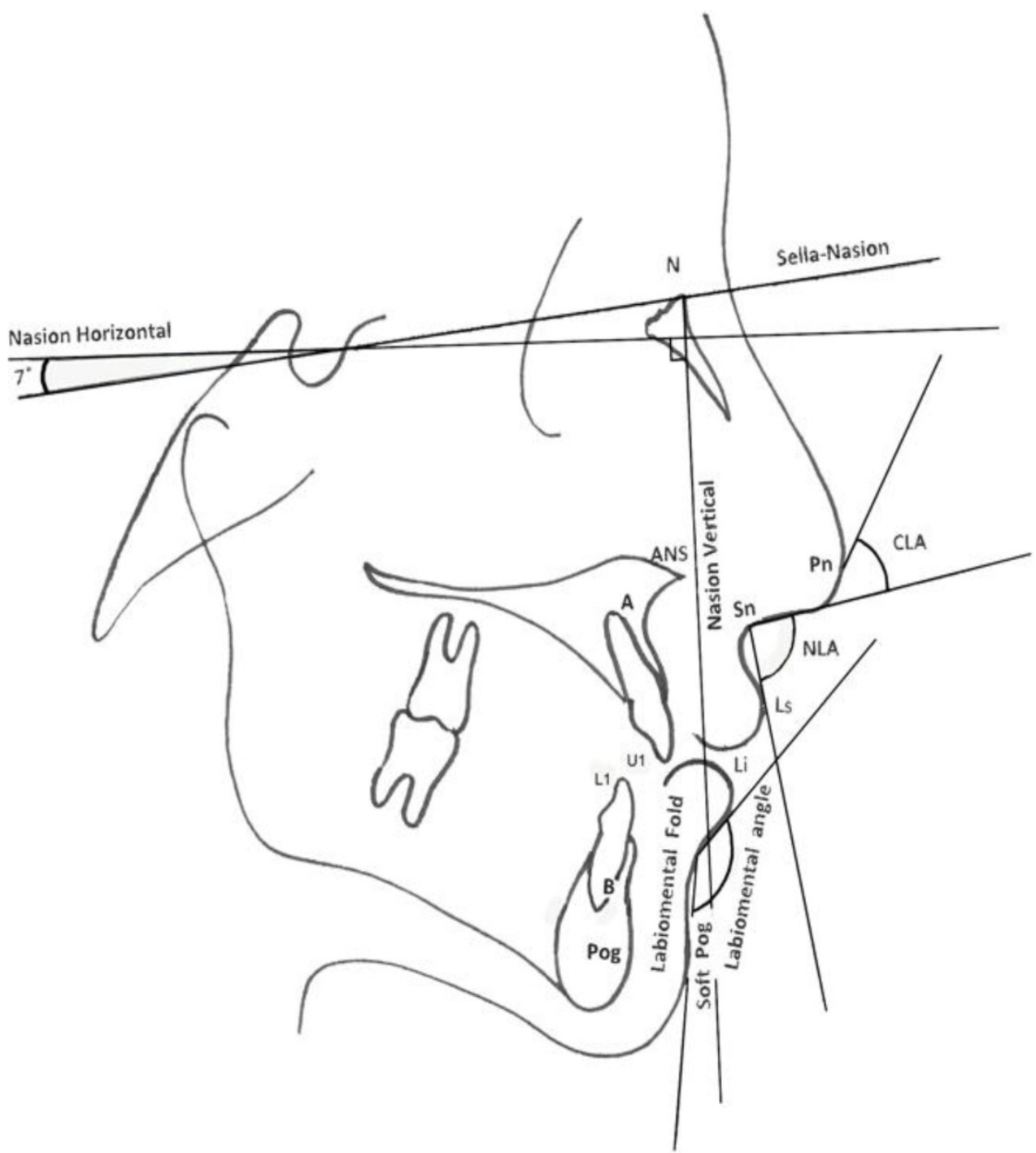

Figure I: Cephalometric landmarks and reference planes. 


\section{Results}

Table 2 shows the averages of the changes observed in skeletal and facial soft tissues after surgery. The average amount of the maxillary impaction and the mandibular advancement were $3.9 \pm 0.7 \mathrm{~mm}$ and $5.88 \pm 6.4 \mathrm{~mm}$, respectively.

There were statistically significant differences between the pre-and post-surgical measurements of APOINTAP (anteroposterior displacement of the A point, mean $3.25 \pm 4.9, \mathrm{p}<0.05$ ), ITIPAP (anteroposteri- or displacement of the upper incisor, mean 2.75 \pm 6.6 , $p<0.05$ ), APOINTSI (superoinferior displacement of the A point, mean $-2.00 \pm 6.3, p<0.05$ ), ITIPSI (superoinferior displacement of the upper incisor, mean $-2.00 \pm 8.7, p<0.05$ ), NASALSI (superoinferior displacement of the nasal point, mean $-1.25 \pm 6.6, p<0.01$ ), BPOINTAP (anteroposterior displacement of the B point, mean $-5.88 \pm 6.4, \mathrm{p}<0.05)$ and the mentolabial angle (mean $-10.38 \pm 6.7, \mathrm{p}<0.05$ ).

Table 2: The averages of the pre- and post-surgical cephalometric measurements.

\begin{tabular}{|c|c|c|c|c|c|c|c|}
\hline & \multirow{2}{*}{\multicolumn{2}{|c|}{$\begin{array}{l}\text { Pre-surgical } \\
\text { (T1) }\end{array}$}} & \multirow{2}{*}{\multicolumn{2}{|c|}{$\begin{array}{l}\text { Post-surgical } \\
\text { (T2) }\end{array}$}} & \multirow{2}{*}{\multicolumn{2}{|c|}{$\begin{array}{l}\text { Difference } \\
\text { (T1-T2) }\end{array}$}} & \multirow[b]{3}{*}{ p } \\
\hline & & & & & & & \\
\hline & Mean & SD & Mean & SD & Mean & SD & \\
\hline APOINTAP (mm) & -7.38 & 4.5 & -4.13 & 5.4 & 3.25 & 4.9 & $0.011^{*}$ \\
\hline ITIPAP (mm) & -6.13 & 6.2 & -.3 .38 & 7.1 & 2.75 & 6.6 & $0.01^{*}$ \\
\hline NASALAP (mm) & 26.63 & 5.0 & 26.25 & 5.2 & -0.38 & 5.1 & 0.61 \\
\hline APOINTSI (mm) & 54.25 & 6.7 & 52.25 & 5.9 & -2.00 & 6.3 & $0.03^{*}$ \\
\hline ITIPSI (mm) & 76.63 & 9.0 & 74.63 & 8.4 & -2.00 & 8.7 & $0.02^{*}$ \\
\hline NASALSI (mm) & 41.75 & 6.4 & 40.50 & 6.3 & -1.25 & 6.6 & $0.008^{*}$ \\
\hline $\operatorname{NLA}\left({ }^{\circ}\right)$ & 104.75 & 16.9 & 103.0 & 11.9 & -1.60 & 14.4 & 0.44 \\
\hline $\operatorname{CLA}\left({ }^{\circ}\right)$ & 30.38 & 5.8 & 29.0 & 6.5 & -1.38 & 6.1 & 0.67 \\
\hline L1TIPAP (mm) & -3.75 & 13.5 & -2.63 & 10.2 & 1.12 & 11.8 & 0.12 \\
\hline L1TIPSI (mm) & 77.25 & 12.3 & 75.38 & 7.7 & -1.83 & 10.0 & 0.09 \\
\hline Labiomental angle & 137.38 & 6.6 & 128.0 & 6.9 & -10.38 & 6.7 & $0.012^{*}$ \\
\hline BPOINTSP (mm) & 98.63 & 14.7 & 96.50 & 8.0 & -2.13 & 11.3 & 0.20 \\
\hline BPOINTAP (mm) & -13.63 & 6.7 & -7.75 & 6.2 & -5.88 & 6.4 & $0.012^{*}$ \\
\hline Soft Pog Vert (mm) & 103.88 & 12.9 & 101.13 & 10.9 & -2.75 & 11.4 & 0.14 \\
\hline
\end{tabular}

$\left(^{*}\right)$ Statistically significant, (Wilcoxon test).

$\mathrm{SD}=$ Standard deviation

\section{Relations between the Facial Soft Tissues and the Hard tissues}

Significant correlations were found between the changes in NASALSI (superoinferior displacement of the nasal point) and NLA ( $\mathrm{r}=0.74, \mathrm{p}<0.05)$; in ITIPAP (anteroposterior displacement of the upper incisor) and CLA (columella lobular angle) $(r=-0.80, p<0.05)$; in Soft Pog Vert (vertical displacement of the soft tissue pogonion) and both BPOINTSP (superoinferior displacement of the $B$ point $)(r=0.72, p<0.05)$ and LTIPSI (superoinferior displacement of the lower incisor) $(\mathrm{r}=0.94, \mathrm{p}<0.001)$ (Table 3$)$.
Table 3: Correlations between the skeletal and soft tissues.

\begin{tabular}{|c|c|c|c|}
\hline & $\operatorname{NLA}\left({ }^{\circ}\right)$ & $\operatorname{CLA}\left({ }^{\circ}\right)$ & Soft Pog Vert \\
\hline \multirow[t]{2}{*}{ NASALSI (mm) } & r 0.74 & & \\
\hline & p $0.03^{*}$ & & \\
\hline \multirow[t]{2}{*}{ ITIPAP (mm) } & & $r-0.80$ & \\
\hline & & p 0.01* & \\
\hline \multirow[t]{2}{*}{ BPOINTSP (mm) } & & & r 0.72 \\
\hline & & & p $0.04^{*}$ \\
\hline \multirow[t]{2}{*}{ LTIPSI (mm) } & & & r 0.90 \\
\hline & & & p $0.0001^{* *}$ \\
\hline
\end{tabular}

(*) Statistically significant, (Pearson correlation test). 


\section{Discussion}

After the 1970s, bimaxillary osteotomy for severe maxillary deformities was performed flourishingly. ${ }^{1-33}$ Several studies were reported on the changes in nasal and soft tissue morphology after bimaxillary osteotomy.1,36,37,41 The morphologic changes in nasal and soft tissues have been assessed by cephalometrics $^{1,2,8,15,20,38}$ stereophotogrammetry ${ }^{7}$ and three dimensional methods $3,16,17,21,35$.

In our study, the study sample presented a homogeneity since all patients were of Turkish origin with a skeletal high angle Class II discrepancy. All patients were treated by Le Fort I maxillary impaction in conjunction with sagittal split osteotomy for mandibular advancement surgery. Rigid fixation was performed in all patients.

A cephalometric evaluation of the craniofacial complex requires a reference plane in order to assess the location of various anatomic structures. For this purpose, the S-N 28 and the Frankfort horizontal planes have been used traditionally. ${ }^{20}$ The S-N plane is the most useful reference plane to assess the changes induced by growth and/or treatment in an individual over time. The low variability in identification of the sella and nasion is an advantage for the use of this plane, as is the fact that sella turcica and nasion represent midsagittal structures. ${ }^{37}$ As an alternative reference plane, Legan et al. ${ }^{9,18,28}$ suggest the use of a line drawn through nasion at an angle of $7^{\circ}$ to the S-N line called a constructed horizontal, which tends to be parallel to true horizontal.

Although significant advances in the stability and predictability of maxillary surgery have been made over years, minimal attention has been paid on the effects of maxillary surgery on the nose and the facial soft tissues. According to Motta et al. ${ }^{3}$, the surface displacements indicate that the postoperative adaptations at different anatomic regions are significantly correlated. Bailey et al. $^{23}$ compared the long-term soft tissue changes occurred in patients underwent either a bilateral sagittal split osteotomy or a Le Fort I osteotomy in conjunction with a bilateral sagittal split osteotomy to those who received only orthodontic treatment. In result, they concluded that although soft tissue changes did occur, there were no significant differences between the average soft tissue changes in the treatment groups. Misir et al. ${ }^{1}$ reported that there was no significant change in NLA and CLA after the maxillary intrusion alone or the maxillary intrusion with protraction. Mommaerts et al. ${ }^{32}$ mentioned that CLA increase after bimaxillary surgery. Gassman et al. ${ }^{38}$ declared that the removal of the anterior nasal spine after the maxillary operation was not significantly related to the changes in nasal morphology. Radney and Jacobs ${ }^{39}$ reported that the NLA changed in response to the amount and the direction of the maxillary movement. In our study, there was no significant change in the NLA and CLA as a result of maxillary impaction. But a significant upper movement of the NASALSI was observed and significant correlations were found between the decreases in NASALSI and NLA. ITIPAP significantly decreased as a result of retrusive movement of upper incisor and it was significantly correlated with an insignificant decrease in CLA.

Vertical displacement of the soft tissue pogonion was significantly correlated with BPOINTSP and LTIPSI. Except for the lip parameters, Ravindranath et al. ${ }^{40}$ reported that the soft tissue cephalometric parameters showed minimal differences after mandibular advancement surgery. One year after mandibular advancement surgery, Almeida et al. ${ }^{41}$ found a significant correlation only between the lower incisor and lower lip. In this study, the anteroposterior position of the BPOINTAP was significantly protruded and mentolabial angle was significantly decreased as a result of mandibular advancement.

\section{Conclusions}

The maxillary impaction led to a nasal protraction, a retraction of the upper lip, which was related to the retraction of the upper incisors, and a superior movement of the soft tissues of the chin. Bilateral sagittal split osteotomy resulted in the counter clockwise rotation of the mandible. In light of these data, we conclude that Le Fort I maxillary impaction in conjunction with mandibular sagittal split osteotomy for mandibular advancement significantly affected the vertical and anteroposterior positions of the maxilla and the mandible, respectively. When performed in combination, these surgical techniques can efficiently alter the position of upper incisor and the nasal position in both vertical and anteroposterior directions. Bimaxillary orthognathic surgery seems to be an efficient method for obtaining satisfactory results in the appearance of the soft, the dental and the skeletal tissues associated with the facial profile in patients with high angle Class II skeletal deformity.

\section{Competing Interests}

The authors have declared that no competing interest exists.

\section{References}

1. Misir AF, Manisali M, Egrioglu E, Naini FB. Retrospective analysis of nasal soft tissue profile changes with maxillary surgery. J Oral Maxillofac Surg 2011; 69: e190-e194. 
2. Potts B, Fields HW, Shanker S, Vig KW, Beck FM. Dental and skeletal outcomes for Class II surgical-orthodontic treatment : A comparison between novice and experienced clinicians. Am J Orthod Dentofacial Orthop 2011; 139: 305-315.

3. Motta AT, Cevidanes LHS, Carvalho FAR, Almeida MA, Philips C. Three-dimensional regional displacements after mandibular advancement surgery: one year of follow-up. J Oral Maxillofac Surg 2011; 69: 1447-1457.

4. Pinho T, Fiqueiredo A. Orthodontic-orthognathic surgical treatment in a patient with Class II subdivision malocclusion: occlusal plane alteration. Am J Orthod Dentofacial Orthop 2011; 140: 703-712.

5. Arad I, Jandu J, Bassett P, Fleming PS. Influence of single-jaw surgery vs bimaxillary surgery on the outcome and duration of combined orthodontic-surgical treatment. Angle Orthod 2011; 81: 983-987.

6. Seah TE, Bellis H, Ilankovan V. Orthognathic patients with nasal deformities: case for simultaneous orthognathic surgery and rhinoplasty. Br J Oral Maxillofac Surg 2012; 50: 55-59.

7. Anic-Milosevic S, Mestrovic S, Prlić A, Slaj M. Proportions in the upper lip-lower lip-chin area of the lower face as determined by photogrammetric method. J Craniomaxillofac Surg 2010; 38: 90-95.

8. Altug-Atac AT, Bolatoglu H, Memikoglu UT. Facial soft tissue profile following bimaxillary orthognathic surgery. Angle Orthod 2008; 78: 50-57.

9. Chew MT, Sandham A, Wong HB. Evaluation of the linearity of soft- to hard tissue movement after orthognathic surgery. Am J Orthod Dentofacial Orthop 2008; 134: 665-670.

10. Collins PC, Epker BN. The alar base cinch: a technique for prevention of alar base flaring secondary to maxillary surgery. Oral Surg Oral Med Oral Pathol 1982; 53: 549-553.

11. Schendel SA, Carlotti AE Jr. Nasal considerations in orthognathic surgery. Am J Orthod Dentofacial Orthop 1991; 100: 197-208.

12. Betts NJ, Vig KW, Vig P, Spalding P, Fonseca RJ. Changes in the nasal and labial soft tissues after surgical repositioning of the maxilla. Int J Adult Orthodon Orthognath Surg 1993; 8: 7-23.

13. Guymon M, Crosby DR, Wolford LM. The alar base cinch suture to control nasal width in maxillary osteotomies. Int J Adult Orthodon Orthognath Surg 1988; 3: 89-95.

14. Westermark AH, Bystedt H, Von Konow L, Sällström KO. Nasolabial morphology after Le Fort I osteotomies. Effect of alar base suture. Int J Oral Maxillofac Surg 1991; 20: 25-30.

15. Rosen HM. Lip-nasal aesthetics following Le Fort I osteotomy. Plast Recons Surg 1988; 81: 171-182.

16. Honrado CP, Lee S, Bloomquist DS, Larrabee WF Jr. Quantitative assessment of nasal changes after maxillomandibular surgery using a 3-dimensional digital imaging system. Arch Facial Plast Surg 2006; 8: 26-35.

17. Ryckman MS, Harrison S, Oliver D, Sandar C, Boryor AA, Hohnmann AA, Kilic F, Kim KB. Soft-tissue changes after maxillomandibular advancement surgery assessed with cone-beam computed tomography. Am J Orthod Dentofacial Orthop 2010; 137: S86-93.

18. Legan HL, Burstone CJ: Soft tissue cephalometric analysis for orthognathic surgery. J Oral Surg 1980; 38: 744-751.

19. Lines PA, Steinhauser EW. Diagnosis and treatment planning in surgical orthodontic therapy. Am J Orthod 1974; 66: 378-397.

20. Mommaerts MY, Marxer H. A cephalometric analysis of the long-term, soft tissue profile changes which accompany the advancement of the mandible by sagittal split ramus osteotomies. J Craniomaxillofac Surg 1987; 15: 127-131.

21. McChance AM, Moss JP, Fright WR, James DR, Linney AD. A three-dimensional analysis of bone and soft tissue to bone ratio of movements in 17 Skeletal II patients following orthognathic surgery. Eur J Orthod 1993; 15: 97-106.

22. Guest E, Berry F, Morris D. Novel methods for quantfying soft tissue changes after orthognathic surgery. Int J Oral Maxillofac Surg 2001; 30: 484-489.

23. Bailey LJ, Collie FM, White RP Jr. Long-term soft tissue changes after orthognathic surgery. Int J Adult Orthodon Orthognath Surg 1996; 11: 7-18.

24. Hajeer MY, Ayoub AF, Millett DT, Bock M, Siebert JP. Three dimensional imaging in orthognathic surgery: the clinical application of a new method. Int J Adult Orthodon Orthognath Surg 2002; 17: 318-330.

25. Moss JP, McChance AM, Fright WR, Linney AD, James DR. A three-dimensional soft tissue analysis of fifteen patients with Class II, Division 1 malocclusions after bimaxillary surgery. Am J Orthod Dentofacial Orthop 1994; 105: 430-437.
26. Day CJ, Robert T. Three-dimensional assessment of the facial soft tissue changes that occur postoperatively in orthognathic patients. World J Orthod 2006; 7: 15-26.

27. Jones JL. Current concepts in aesthetic orthognathic surgery. Facial Plast Surg. 1999; 15: 13-24.

28. Mansour S. Burstone C, Legan H. An evaluation of soft tissue changes resulting from LeFort I maxillary surgery. Am J Orthod. 1983; 84: 37-47.

29. Jensen AC, Sinclair PM, Wolford LM. Soft tissue changes associated with double jaw surgery. Am J Orthod Dentofacial Orthop. 1992; 101: 266-275.

30. Oliver BM. The influence of lip thickness and strain on upper lip response to incisor retraction. Am J Orthod 1982; 82: 141-149.

31. Mitchell C, Oelthien J, Panthaki Z, Thaller SR. Nasolabial esthetics. J Craniofac Surg 2007; 18: 756-765.

32. Mommaerts MY, Abeloos JV, De Clercq CA, Neyt LF. The effects of the subspinal Le Fort I-type osteotomy on interalar rim width. Int J Adult Orthodon Orthognath Surg 1997; 12: 95-100.

33. Yamada T, Mishima K, Moritani N, Janune D, Matsumura T, Ikeya Y, Yamamoto T. Nasolabial morphologic changes after a Le Fort I osteotomy: a three-dimensional anthropometric study. J Craniofac Surg 2010; 21: 1089-1095.

34. Nkenke E, Langer A, Laboureux X, Benz M, Maier T, Kramer M, Häusler G, Kessler P, Wiltfang J, Neukam FW. Validation of in vivo assessment of facial soft tissue volume changes and clinical application in midfacial distraction: a technical report. Plast Recons Surg 2003; 112: 367-380.

35. Kim YI, Kim JR, Park SB. Three-dimensional analysis of midfacial soft tissue changes according to maxillary superior movement after horizontal osteotomy of the maxilla. J Craniofac Surg 2010; 21: 1587-1590.

36. Bland JM, Altman DG. Statistical methods for assessing agreement between two methods of clinical measurement. Int J Nurs Stud 2010; 47: 931-936.

37. Ellis E 3rd, McNamara J Jr. Cephalometric reference planes--sella nasion vs Frankfort horizontal. Int J Adult Orthod Orthognath Surg 1988; 3: 81-87.

38. Gassman CJ, Nishioka GJ, Van Sickels JE, Thrash WJ. A lateral cephalometric analysis of nasal morphology following Le Fort I osteotomy applying photometric analysis techniques. J Oral Maxillofac Surg 1989; 47: 926-930.

39. Radney LJ, Jacobs JD. Soft tissue changes associated with surgical total maxillary intrusion. Am J Orthod 1981; 80: 191-212.

40. Ravindranath S, Krishnaswamy NR, Sundaram V. Comparison of two imaging programs in predicting the soft tissue changes with mandibular advancement surgery. Orthodontics (Chic.) 2011; 12: 354-365.

41. Almeida RC, Cevidanes LH, Carvalho FA, Motta AT, Almeida MA, Styner M, Turvey T, Proffit WR, Philips C. Soft tissue response to mandibular advancement using 3D CBCT scanning. Int J Oral Maxillofac Surg 2011; 40: 353-359. 